Sources of semiochemicals mediating host finding in Callosobruchus chinensis (Coleoptera : Bruchidae)

Journal Article

Author(s):

Azariah, Babu; Hern, Alan; Dorn, Silvia

Publication date:

2003-06

Permanent link:

https://doi.org/10.3929/ethz-b-000055818

Rights / license:

In Copyright - Non-Commercial Use Permitted

Originally published in:

Bulletin of Entomological Research 93(3), https://doi.org/10.1079/BER2003231 


\title{
Sources of semiochemicals mediating host finding in Callosobruchus chinensis (Coleoptera: Bruchidae)
}

\author{
A. Babu ${ }^{\dagger}$, A. Hern and S. Dorn* \\ Institute of Plant Sciences, Applied Entomology, Swiss Federal Institute of \\ Technology (ETH), Clausiusstrasse 25/NW, CH-8092 Zürich, Switzerland
}

\begin{abstract}
Bruchid pests such as Callosobruchus chinensis (Linnaeus) endanger stored legume seeds throughout the tropical belt. The chemical composition of the headspace volatiles from healthy and fourth instar larvae-infested cowpea seeds were identified, characterized, and compared using gas chromatography-mass spectrometry. Y-tube olfactometer bioassays were performed to evaluate the effect of these chemicals on the orientation of conspecific adult females. Analysis of volatiles released from healthy and infested seeds revealed qualitative differences for three out of the 17 compounds identified. Dimethyl disulphide, isobutenyl methyl ketone and methyl trisulphide were found only in the blend emitted from infested but not from healthy seeds. Quantitative differences were apparent for tridecane which was released in larger amounts from infested seeds. While volatiles collected from healthy seeds were attractive to female bruchids, volatiles collected from infested seeds were repellent. To test the hypothesis that the qualitative differences in the chemical composition found may be due to insectderived components, the volatiles from frass and fourth instar larvae combined were analysed. These volatiles contained both of the sulphides emitted from infested seed but not from healthy seeds. Although a limited induction of volatiles from cowpea seeds cannot be excluded, it is postulated that behavioural differences of the female weevils are largely due to insect-derived semiochemicals. The potential use of such semiochemicals as part of an integrated pest management strategy is discussed.
\end{abstract}

\section{Introduction}

Bruchids are the major pest of stored legumes across the tropical belt (Abate \& Ampofo, 1996; Abate et al., 2000; Schmale et al., 2001, 2003). Losses due to bruchids account for 20-60\% of stored seeds (Agarwal et al., 1988; Mbata et al., 2000; Raja et al., 2001). As legumes are a major source of protein in the developing world, damage by bruchids causes a serious problem.

*Author for correspondence

Fax: +4116321171

E-mail: silvia.dorn@ipw.agrl.ethz.ch

†Present address: Entomology Research Institute, Loyola

College, Chennai, 600 034, India
Natural resources may represent easily accessible tools to protect stored legume seeds from bruchid attack. Extracts from non-host plants have been identified with lethal or behavioural effects on bruchids (Agarwal et al., 1988; Raja et al., 2001). Also investigated were the effects of phagostimulants and oviposition stimulants in stored product pests (Kanauija \& Levinson, 1981). The use of semiochemicals in bruchid management has focused on oviposition-deterring pheromones (Messina et al., 1987) and on sex pheromones (Mbata et al., 1999, 2000). Cork et al. (1991) provided the first lead into structures of Callosobruchus pheromones. Chemicals mediating insect-plant interactions have not yet been explored for bruchid control. Bruchids appear to make use of olfactory stimuli in host location. For example, female Callosobruchus chinensis (Linnaeus) (Coleoptera: Bruchidae) 
are attracted to healthy seeds but not to seeds infested with conspecific larvae (Ignacimuthu et al., 2000). When given the choice between volatiles from healthy seeds and seeds infested by larvae, conspecific females preferred the healthy seeds (Ignacimuthu et al., 2000).

Many herbivore-infested plants emit a different blend of volatiles in comparison to healthy plants (see Dicke, 1999). When a plant is attacked by a herbivore it may become either more or less attractive than a comparable healthy plant (reviewed by Sabelis et al., 1999; Hern \& Dorn, 2002). These differences can be due to volatile chemicals derived from the herbivore and its frass, or from the induced plant. While the composition of such volatiles from growing plants has received broad attention (Dicke, 1999; Paré \& Tumlinson, 1999), little is known regarding chemicals released from grain legumes upon herbivory and their effect on adult storage pests. Studies on interactions between stored grains and insects focus on wheat-parasitoid relationships (Steidle \& Schöller, 1997; Ruther \& Steidle, 2000; Steidle, 2000; Steidle \& Fischer, 2000).

As semiochemicals have been shown to exert dramatic effects on the behaviour of herbivore pests, interest in their use in pest management is growing (Agelopoulos et al., 1999). In storage, they could either be used as attractants for monitoring and/or control, or as repellents to establish an olfactory barrier to reduce the immigration of bruchids into storage sacks.

In this study, volatiles from cowpea seeds infested with fourth instar $C$. chinensis larvae were identified and compared with emissions from healthy seeds. Bioassays were carried out to explore the olfactory response of $C$. chinensis females to these volatile blends. This is a first step in the search for candidate semiochemicals mediating insect-plant interactions for potential use in bruchid pest management.

\section{Materials and methods}

\section{Test insects}

Callosobruchus chinensis were obtained from the Federal Biological Research Centre for Agriculture and Forestry, Institute Stored Product Protection, Berlin, Germany. They were maintained on cowpea seeds (Vigna unguiculata (L.) (Fabaceae)) at $25^{\circ} \mathrm{C}, 60 \%$ r.h. and L16:D8 in the laboratory. Beetles were sexed (Pandey \& Singh, 1997) and placed in Plexiglas boxes for $24 \mathrm{~h}$ before introducing them for infestation.

\section{Host seeds}

Pre-washed seeds of cowpea $V$. unguiculata were obtained from a commercial supplier. Care was taken to ensure that the cowpeas used in all the experiments were free from initial infestation.

\section{Infestation}

For each replicate, $200 \mathrm{~g}$ of cowpeas were exposed to 2day-old C. chinensis (300 females and 100 males) for a period of $48 \mathrm{~h}$ to produce a uniform infestation. The adult bruchids were removed and the cowpeas were stored under the same conditions as mentioned above. Under these conditions, the fourth instar larvae pupate at day 15-17 (Ignacimuthu et al., 2000). For the control, $100 \mathrm{~g}$ of healthy cowpea seeds were separated from the stock and kept separately under the same conditions.

\section{Volatile collection}

Volatile collections were made from healthy seeds and seeds infested with fourth instar C. chinensis larvae. Headspace volatiles were collected by taking $100 \mathrm{~g}$ of cowpea seeds. An activated-charcoal filtered airflow, of $450 \mathrm{ml} \mathrm{min}{ }^{-1}$ generated by a suction pump, entered one end of a dilated glass tube (length $35 \mathrm{~cm}$, diameter $6 \mathrm{~cm}$ ) and passed over the seeds. All volatiles were collected using $3 \times$ 0.25 inch stainless steel thermal desorption tubes filled with $300 \mathrm{mg}$ Tenax-GR (mesh size 60/80), plugged with glass wool (unsilanized) at either end and stainless steel mesh. The tubes were conditioned with helium (purity 99.96\%)

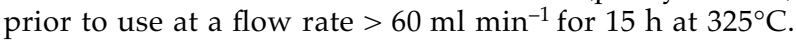
Conditioned traps were stored with brass end caps (PTFE ferrules) in a glass air-tight jar with a small amount of activated charcoal.

Two collections were made from each set of seeds. The first lasted $4 \mathrm{~h}$, used all of the $100 \mathrm{~g}$ of seeds and was subsequently analysed by gas chromatography-mass spectrometry (GC-MS). The second set of collections lasted $24 \mathrm{~h}$ and used $90 \mathrm{~g}$ of seeds, as $10 \mathrm{~g}$ of seeds were removed prior to the second set of volatile collections from both the healthy and infested seeds. These were used to estimate the degree of infestation as well as the developmental stage of the larvae based on head capsule widths (Won \& Ryoo, 1994). These data suggest that virtually all (>98\%) of the seeds used contained at least one fourth instar $C$. chinensis larva. After the 24-h collections, volatiles were eluted from the traps with $1 \mathrm{ml}$ hexane $(99.5 \%)$. The samples obtained by solvent elution were stored at $-60^{\circ} \mathrm{C}$ in glass vials and were used for bioassays.

Gas chromatography-mass spectrometry analysis was carried out using a Hewlett Packard gas chromatograph (6890) coupled to a mass selective detector (5973). The oven programme was as follows: initial temperature was $40^{\circ} \mathrm{C}$ for $3 \mathrm{~min}$, then ramped at a rate of $8^{\circ} \mathrm{C} \mathrm{min}^{-1}$ to the final temperature $220^{\circ} \mathrm{C}$. The column was fitted with a $250 \mu \mathrm{m}$ retention gap (5 m long); $30 \mathrm{~m}$ Altech Econocap Column, 250 $\mu \mathrm{m}$ diameter; film thickness $2.3 \mu \mathrm{m}$ phase EC-5 (5\% phenyl95\% methyl-polysiloxane) with a flow rate of approximately $1.5 \mathrm{ml} \mathrm{min}^{-1}$ at $40^{\circ} \mathrm{C}$. The GC-MS transfer-line was held at a temperature of $280^{\circ} \mathrm{C}$ with the mass selective detector operated in scan mode. The volatiles were transferred to the GC-MS by thermal desorption using a Unity instrument (Markes International, Pontyclun, UK). Tenax-GR traps were desorbed for $3 \mathrm{~min}$ at a temperature of $300^{\circ} \mathrm{C}$, with the desorb flow at $30 \mathrm{ml} \mathrm{min} \mathrm{m}^{-1}$. The cold trap was a split bed trap filled with a $4 \mathrm{~cm}$ bed of Tenax-TA and a $2 \mathrm{~cm}$ bed of Carbopack B (both sorbents had a mesh size of $60 / 80$ ). It was held at $-10^{\circ} \mathrm{C}$ for the whole of the sample trap desorption and was then heated at a rate of $40^{\circ} \mathrm{C} \mathrm{sec}^{-1}$ for 3 min to a maximum temperature of $300^{\circ} \mathrm{C}$. The thermal desorption instrument was operated with a split flow during both the initial sample tube desorption and also during the cold trap desorption. The total split flow ratio was 1.5. The transfer line between the gas chromatograph and the thermal desorber was a fused silica column $(320 \mu \mathrm{m}$ in diameter and approximately $1 \mathrm{~m}$ long) held at $150^{\circ} \mathrm{C}$. Identification of compounds was based on retention time matching and coinjection with standards. Standards for this purpose were purchased from Sigma, Aldrich, Supelco and ACROS. Compounds marked with a ' + ' in fig. 1 indicate a tentative identification based on the NIST98 mass spectral database. 
Volatiles from frass and larvae combined were analysed using direct thermal desorption as follows: infested seeds as above were frozen at $-20^{\circ} \mathrm{C}$ and 30 fourth instar $C$. chinensis larvae $(c .100 \mathrm{mg})$ and frass $(c .7 .5 \mathrm{mg})$ were removed from the beans. These were placed in a Silcosteel thermal desorption tube (Markes International, Pontyclun, UK) plugged with glass wool. The empty tube and glass wool were conditioned as above for $1 \mathrm{~h}$ prior to filling. The tube was placed in the thermal desorption instrument and volatiles were collected onto the cold trap for a period of 90 min at $40^{\circ} \mathrm{C}$. The cold trap was held at $-10^{\circ} \mathrm{C}$ throughout this period and then desorbed as above thereby transferring retained volatiles into the GC-MS operated as above.

Data were analysed using a randomization test (Potvin \& Roff, 1993; Conover, 1999). The test was performed with a Macro for Microsoft Excel developed by Horgan \& Rouault (2000). The test used 5000 randomizations and was run using Excel 2001 on a G4 power Macintosh (Operating System 9.2).

\section{Olfactometer bioassays}

A Y- tube olfactometer was used (length of common arm $24 \mathrm{~cm}$, of each branch $14.5 \mathrm{~cm}$; diameter $3 \mathrm{~cm}$ ). Bioassays were carried out with a light intensity of 720 lux, a temperature of $22-24^{\circ} \mathrm{C}$ and an airflow of $450 \mathrm{ml} \mathrm{min}^{-1}$ into each arm of the olfactometer. All the bioassays were conducted in the morning between 09.00 and $11.00 \mathrm{~h}$ with 23 insects tested each day. Four- to five-day-old mated females were used in the bioassays. For mating, bruchids of both sexes were placed in Plexiglas boxes upon emergence and provided with a $10 \%$ honey solution $(\mathrm{w} / \mathrm{v})$ as a food source (Ignacimuthu et al., 2000). Volatiles from healthy and from fourth instar $C$. chinensis larvae infested beans were compared to hexane controls. Individual females were introduced into the central tube $2 \mathrm{~cm}$ from the start line using a fine brush. The behaviour of the bruchids was classified as one of three categories choosing between hexane or the treatment volatiles or 'no choice' (individuals which had not made a choice for either odour within $2 \mathrm{~min}$ of crossing the start line). Twenty-five microlitres of test chemical was placed on a Silicon/Teflon septum (11 $\mathrm{mm}$ in diameter; Hewlett Packard). Fresh chemicals on new septa were used for each weevil. To minimize pseudoreplication of the olfactometer bioassays, a different set of volatiles for both the healthy and herbivore infested treatments were used for each day's bioassays. Preferences for an odour were tested using a single sample $\chi^{2}$ test (Zar, 1998).

\section{Results}

The volatile compounds identified from the cowpea seeds were a mixture of aldehydes, hydrocarbons, ketones and sulphides (fig. 1). Significant differences between the composition of healthy and C. chinensis-infested seeds were apparent for four out of the 17 compounds: dimethyl disulphide $(P=0.006$; $\mathrm{SE}=0.001)$; methyl trisulphide $(P=$ 0.012 ; $\mathrm{SE}=0.002)$; isobutenyl methyl ketone $(P=0.004$; $\mathrm{SE}=$ $0.001)$ and tridecane $(P=0.015$; SE $=0.002)$. Both of the sulphides and isobutenyl methyl ketone were never detected in the healthy seeds and were only found in the seeds infested by the bruchid larvae. Emissions of tridecane showed a four-fold increase upon herbivory in the infested seeds compared to healthy seeds. The remaining hydrocarbons, terpenoids and aldehydes were found in both categories of seeds in similar quantities.

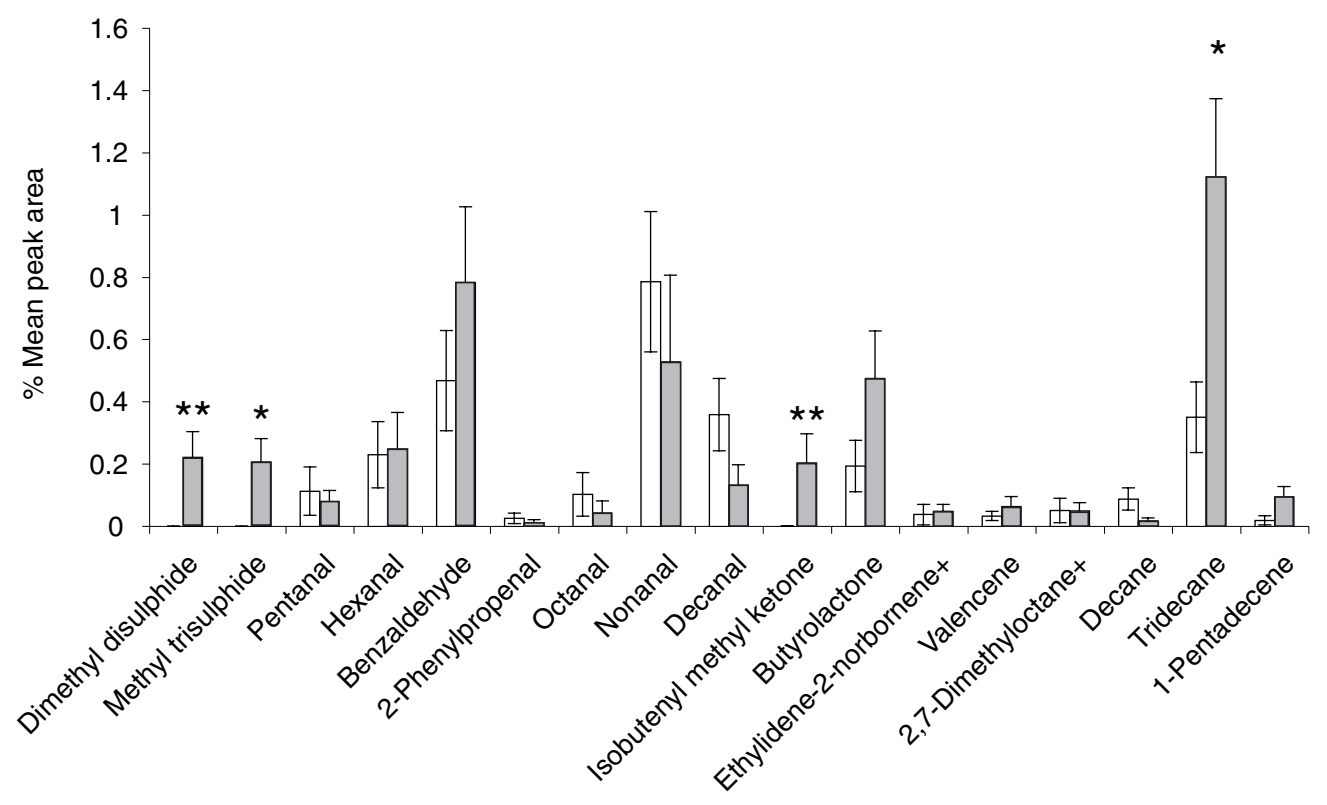

Fig. 1. Percentage of mean peak area of volatiles collected from healthy cowpeas ( $\square$ ) and those infested with fourth instar Callosobruchus chinensis larvae ( $\square$ ). $\mathrm{N}=8$ for each treatment; * $P<0.05$; ${ }^{* *} P<0.01$ randomization test. ' + ' indicates a tentative identification based on a comparison of the sample spectra with a mass spectral library. 
The volatile emissions from bruchid larvae and frass (table 1) consisted of the sulphurous compounds dimethyl disulphide, methyl trisulphide and dimethyl sulphone, and benzaldehyde and 2,3-butanediol (table 1).

In the Y-tube olfactometer bioassays, female $C$. chinensis exhibited a significant preference for the odour of healthy cowpea seeds compared to the solvent control $\left(\chi^{2}=34 ; \mathrm{DF}=\right.$ $1 ; P<0.001$; fig. 2). In contrast, cowpea seeds infested with fourth instar $C$. chinensis larvae were repellent to conspecific adult females as compared to the solvent control $\left(\chi^{2}=34\right.$; DF $=1 ; P<0.001)$. The percentage of bruchids not making a choice for either odour was 18 and 36, respectively, for healthy and infested cowpea seeds.

\section{Discussion}

The relative amounts of four compounds collected from cowpea seeds infested by fourth instar C. chinensis larvae differed in comparison to those from healthy seeds. Three of these compounds, dimethyl disulphide, methyl trisulphide and isobutenyl methyl ketone, were not detected in the healthy cowpea samples. The fourth compound, tridecane, occurred at much higher quantities in the volatiles from infested than from healthy seeds. The compounds found only in the infested seeds were either synthesized de novo by the plant upon herbivory or are insect derived. As analysis of frass and larvae of $C$. chinensis from infested cowpeas indicated that both of the sulphides were present, it is concluded that these compounds are of insect origin. For the third compound, the ketone, either hypothesis is plausible. The major compound found in the analyses of frass and larvae was butane diol representing over $75 \%$ of the total composition of the volatile profiles. This contrasts with the analyses of infested seeds carried out with a different method in which butane diol was never detected. It seems to be a compound primarily associated with insect frass. As reported for an endophytic sawfly Hoplocampa testudinea Klug (Hymenoptera: Tenthredinidae) feeding on apple fruits (Boevé et al., 1996), abundant amounts of the compound were found in frass samples, but none in samples of infested fruits.

The bioassays show that volatiles from cowpeas infested with fourth instar $C$. chinensis larvae are clearly repellent to conspecific females. These volatiles were collected on Tenax and eluted with solvent. While only a few bruchid beetles entered the olfactometer arm with these volatiles, a large proportion of the females remained either in the central tube, making 'no-choice', or entered the olfactometer arm with the solvent control, thus moving away from the test odour source. Similarly, adult female codling moth, Cydia pomonella (Linnaeus) (Lepidoptera: Tortricidae), moved away from the

Table 1. Percentage composition of volatiles collected from fourth instar Callosobruchus chinensis larvae and frass combined using direct thermal desorption.

\begin{tabular}{lc}
\hline Compound & Mean $\pm \mathrm{SE}$ \\
\hline Dimethyl disulphide & $2 \pm 0.15$ \\
Methyl trisulphide & $0.1 \pm 0.1$ \\
Dimethyl sulphone & $2.2 \pm 0.15$ \\
Benzaldehyde & $0.26 \pm 0.13$ \\
2,3-Butanediol & $76 \pm 2.2$ \\
\hline
\end{tabular}

Mean values $\pm \mathrm{SE}, \mathrm{N}=2$. volatiles containing a high dose of the inducible plant volatile E, E- $\alpha$-farnesene and entered the olfactometer arm with the solvent control, while the opposite occurred in response to a low dose of this terpene (Hern \& Dorn, 1999). The repellency and the attraction exhibited by characteristic doses of this semiochemical were assumed to reflect the gravid female's response to unfavourable and favourable conditions, respectively (Hern \& Dorn, 1999). In the present study, the effect of larval infestation was tested at the end of larval development, while a previous study showed that an effect is already measurable at the beginning of larval development. When given the choice between seeds infested with first instar larvae and healthy seeds, female Callosobruchus chinensis showed an olfactory preference for the healthy seeds, while they did not discriminate between egg infested and healthy seeds (Ignacimuthu et al., 2000). This adds further credence to the hypothesis that the feeding larvae within the seeds are directly and/or indirectly responsible for the production of volatiles which cause the repellency observed. In contract to our results, Ignacimuthu et al. (2000) found neither repellency nor attraction in a choice experiment between seeds infested with larvae and clean air, but the level of responding females was very low. Again consistently, the bioassays described here and those reported by Ignacimuthu et al. (2000) demonstrated that healthy cowpeas are attractive to $C$. chinensis. Fourteen compounds in the headspace of healthy seeds were identified, some of which are reported in the headspace of cowpea plants, as for example, nonanal and hexanal (Lwande et al., 1989).

In different systems there is a coincidence between the repulsion of conspecific herbivores and the attraction of parasitoids to herbivore-infested plants (Sabelis et al., 1999). A larval parasitoid of the granary weevil, Sitophilus granarius (Linnaeus) (Coleoptera: Curculionidae), prefers infested wheat grain over uninfested wheat. The cues utilized by the parasitoid Lariophagus distinguendus (Förster) (Hymenoptera: Pteromalidae) are related to the frass of the granary weevil (Steidle \& Schöller, 1997; Steidle \& Ruther, 2000). There was also a clear positive dose-response between the amount of frass extract tested and the behavioural response of experienced parasitoids (Steidle \& Fischer, 2000). With the current system, one could test the response of parasitoids to the volatiles using Dinarmus basalis (Rondani) (Hymenoptera:

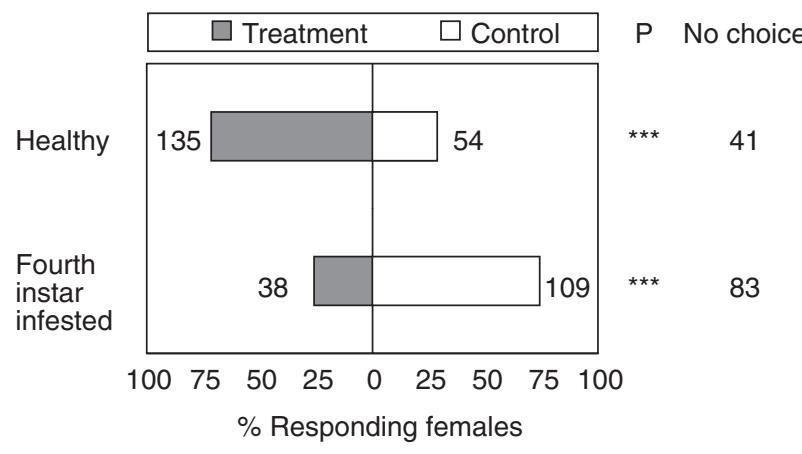

Fig. 2. Response of female Callosobruchus chinensis in a Y-tube olfactometer to volatiles from healthy or fourth instar C. chinensis-infested cowpea seeds versus solvent. The numbers indicate the number of individuals that made no choice or preferred one of the two volatiles (treatment or solvent control). $\mathrm{N}=230 .{ }^{* * *} P<0.001$; single sample $\chi^{2}$ test. 
Pteromalidae), a promising antagonist of several bruchid pests (Schmale et al., 2001, and literature quoted therein).

While the data presented suggest that the sulphides in the headspace of infested cowpea seeds are of insect origin, the ketone which was never found in healthy seeds may be of plant origin as it was not detected in the frass or larvae of the bruchid analysed. There is ample evidence showing that in leguminous plants, herbivore induction of host plant volatiles is a common phenomenon (Dicke, 1999). In cowpea plants, the green leaf volatiles Z-3-hexen-1-ol and Z-3hexenyl acetate both appear to be induced by larvae of Heliothis zea (Boddie) (Lepidoptera: Noctuidae) feeding on the leaves of the plant (Whitman \& Eller, 1990).

Tridecane was found in higher amounts following herbivory of stored seeds. The fact that it was the only compound showing a quantitative change and that this hydrocarbon was not detected in the frass-larvae analyses suggests that it is plant rather than insect-derived. In this study, volatile emissions from stored seeds were analysed which had been infested for up to 14 days since oviposition. Another study by Hern \& Dorn (2001) showed that ripe, stored apple fruits are capable of exhibiting an induction of volatiles following attack by an endophytic herbivore. Over the course of larval development of Cydia pomonella the quantities of volatiles from infested apples were higher for the first 3-6 days, then decreased to a similar or lower level as compared to emissions from healthy fruits 9-21 days after infestation. Results from cowpeas indicate that such possible herbivore induction did not occur for the majority of compounds, and that the major changes in the volatile profiles cannot be attributed to induction.

The identified semiochemicals can form the basis for further studies aimed at developing an olfactory system for monitoring or control of these bruchids. The repellents are most likely of insect origin, associated with the frass. The attractants are clearly of plant origin, and selected components of the natural blend may be effective for trapping $C$. chinensis females.

\section{Acknowledgements}

The authors are thankful to the Novartis (Syngenta) Foundation for Sustainable Development, Basel, for financial support. The randomization tests were conducted using an Excel Macro developed by Dr G. Horgan and J. Rouault of Biostatistics and Mathematics Scotland, James Clerk Maxwell Building, The King's Buildings, West Mains Road, Edinburgh, EH9 3JZ. We thank Professor S. Ignacimuthu (Loyola College, Chennai, India) for useful discussions and Dr K. Tschudi-Rein (Applied Entomology, ETH Zürich) for comments on the manuscript.

\section{References}

Abate, T. \& Ampofo, J.K.O. (1996) Insect pests of common bean in Africa: their ecology and management. Annual Review of Entomology 41, 45-73.

Abate, T., van Huis, A. \& Ampofo, J.K.O. (2000) Pest management strategies in traditional agriculture: an African perspective. Annual Review of Entomology 45, 631-659.

Agarwal, A., Lal, S. \& Gupta, K.C. (1988) Natural products as protectants of pulses against pulse beetles. Bulletin of Grain Technology 26, 154-164.
Agelopoulos, N., Birkett, M.A., Hick, A.J., Hooper, A.M., Pickett, J.A., Pow, E.M., Smart, L.E., Smiley, D.W.M., Wadhams, L.J. \& Woodcock, C.M. (1999) Exploiting semiochemicals in insect control. Pesticide Science 55, 225-235.

Boevé, J.L., Lengwiler, U., Tollsten, L., Dorn, S. \& Turlings, T.C.J. (1996) Volatiles emitted by apple fruitlets infested by larvae of the European apple sawfly. Phytochemistry 42, 373-381.

Conover, W.J. (1999) Practical nonparametric statistics, 3rd edn. 584 pp. New York, John Wiley and Sons, Inc .

Cork, A., Hall, D.R., Blaney, W.M. \& Simmonds, M.S.J. (1991) Identification of a component of the female sex pheromone of Callosobruchus analis (Coleoptera: Bruchidae). Tetrahedron Letters 32, 129-132.

Dicke, M. (1999) Are herbivore-induced plant volatiles reliable indicators of herbivore identity to foraging carnivorous arthropods? Entomologia Experimentalis et Applicata 91, 131-142.

Hern, A. \& Dorn, S. (1999) Sexual dimorphism in the olfactory orientation of adult Cydia pomonella in response to $\alpha$ farnesene. Entomologia Experimentalis et Applicata 92, 63-72.

Hern, A. \& Dorn, S. (2001) Induced emissions of apple fruit volatiles by the codling moth: changing patterns with different time periods after infestation and larval instars of the herbivore. Phytochemistry 57, 409-416.

Hern, A. \& Dorn, S. (2002) Induction of volatile emissions from ripening fruits infested with Cydia pomonella and the attraction of adult females. Entomologia Experimentalis et Applicata 102, 145-151.

Horgan, G.W. \& Rouault, J. (2000) Introduction to randomisation tests. http://www.bioss.ac.uk/smart/ unix/mrandt/slides/frames.htm

Ignacimuthu, S., Wäckers, F.L. \& Dorn, S. (2000) The role of chemical cues in host finding and acceptance by Callosobruchus chinensis. Entomologia Experimentalis et Applicata 96, 213-219.

Kanaujia, K.R. \& Levison, H.Z. (1981) Phagostimulatory responses and oviposition behavor of Sitophilus granarius L. to newly harvested and stored wheat grains. Zeitschrift für Angewandte Entomologie 91, 417-424.

Lwande, W., McDowell, P.G., Amiani, H. \& Amoke, P. (1989) Analysis of airborne volatiles of cowpea. Phytochemistry 28, 421-423.

Mbata, G.N., Shu, S. \& Ramaswamy, S.B. (1999) Responses of normal and active males of Callosobruchus subinnotatus to female sex pheromone. Annals of the Entomological Society of America 92, 594-600.

Mbata, G.N., Shu, S. \& Ramaswamy, S.B. (2000) Sex pheromones of Callosobruchus subinnotatus and C. maculatus (Coleoptera: Bruchidae): congeneric responses and role of air movement. Bulletin of Entomological Research 90, 147-154.

Messina, F.J., Barmore, J.L. \& Renwick, J.A.A. (1987) Oviposition deterrent from eggs of Callosobruchus maculatus: spacing mechanism or artifact? Journal of Chemical Ecology 13, 219-225.

Paré, P.W. \& Tumlinson, J.H. (1999) Plant volatiles as a defense against insect herbivores. Plant Physiology 121, 325-331.

Potvin, C. \& Roff, D.A. (1993) Distribution-free and robust statistical methods: viable alternatives to parametric statistics. Ecology 74, 1617-1628.

Raja, N., Albert, S., Ignacimuthu, S. \& Dorn, S. (2001) Effect of plant volatile oils in protecting stored cowpea Vigna unguiculata (L.) Walpers against Callosobruchus maculatus 
(F.) (Coleoptera: Bruchidae) infestation. Journal of Stored Products Research 37, 127-132.

Ruther, J. \& Steidle, J.L.M. (2000) Mites as matchmakers: semiochemicals from host-associated mites attract both sexes of the parasitoid Lariophagus distinguendus. Journal of Chemical Ecology 26, 1205-1217.

Sabelis, M., Janssen, A., Pallini, A., Venzon, M., Bruin, J., Drukker, B. \& Scutareanu, P. (1999) Behavioural responses of predatory and herbivorous arthropods to induced plant volatiles: from evolutionary ecology to agricultural applications, pp. 269-296 in Agrawal, A.A., Tuzun, S. \& Bent, E. (Eds) Induced plant defenses against pathogens and herbivores biochemistry, ecology and agriculture. St Paul, Minnesota, APS Press.

Schmale, I., Wäckers, F.L., Cardona, C. \& Dorn, S. (2001) Control potential of three hymenopteran parasitoid species against the bean weevil in stored beans: the effect of adult parasitoid nutrition on longevity and progeny production. Biological Control 21, 134-139.

Schmale, I., Wäckers, F.L., Cardona, C. \& Dorn, S. (2003) Combining parasitoids and plant resistance for the control of the bruchid weevil Acanthoscelides obtectus in stored beans. Journal of Stored Products Research 39, 401-411.

Steidle, J.L.M. (2000) Host recognition cues of the granary weevil parasitoid Lariophagus distinguendus. Entomologia Experimentalis et Applicata 95, 185-192.

Steidle, J.L.M. \& Fischer, A. (2000) Quantity does matter: how feces are used for host stage selection by granary weevil parasitoid Lariophagus distinguendus. Journal of Chemical Ecology 26, 2657-2664.

Steidle, J.L.M. \& Ruther, J. (2000) Chemicals used for host recognition by the granary weevil parasitoid Lariophagus distinguendus. Journal of Chemical Ecology 26, 2665-2675.

Steidle, J.L.M. \& Schöller, M. (1997) Olfactory host location and learning in the granary weevil parasitoid Lariophagus distinguendus. Journal of Insect Behavior 3, 331-342.

Whitman, D.W. \& Eller, F.J. (1990) Parasitic wasps orient to green leaf volatiles. Chemoecology 1, 69-75.

Won, I.C. \& Ryoo, M.I. (1994) Classifying instars of adzuki bean weevils (Bruchidae: Coleoptera) based on head capsule widths. Korean Journal of Entomology 24, 155-157.

Zar, J.H. (1998) Biostatistical analysis. 4th edn. London, Prentice Hall International.

(Accepted 31 December 2002)

(C) CAB International, 2003 